\title{
Chronic illness, self-management, and technology: type I diabetes patients' views of the use of technology to communicate with health professionals about their disease
}

\author{
This article was published in the following Dove Press journal: \\ Patient Intelligence \\ 21 November 2012 \\ Number of times this article has been viewed
}

\author{
Annmarie Ruston' \\ Alison Smith' \\ Bernard Fernando 2 \\ 'Centre for Health and Social Care \\ Research, Faculty of Health and \\ Social Care, Canterbury Christ \\ Church University, Chatham Maritime, \\ United Kingdom; ${ }^{2}$ Thames Avenue \\ Surgery, Rainham, United Kingdom
}

Purpose: Diabetes represents one of the greatest health challenges facing the UK. Telehealth is seen to have the potential to revolutionize health care provision by improving access for patients with chronic disease, reducing health care costs, and improving efficiency. There have been many trials of telehealth in the UK but these have typically failed to become part of routine health care, particularly for diabetics. Program design and implementation has not been grounded in an understanding about the ways in which patients manage their disease and perceive these new technologies. This study addresses this gap by gaining an understanding of the perceptions of patients with type 1 diabetes about how telehealth could be used as part of their health care.

Patients and methods: Thirty-two people with type 1 diabetes were recruited from a database of insulin pump users, and in-depth telephone interviews were undertaken, tape recorded, and transcribed. Analysis was conducted using a constant comparative approach.

Results: Although respondents used technology as part of their diabetes self-management, they considered that the use of telehealth, as part of their health care, was potentially of limited value. Three themes emerged from their discourses: (1) a need to be in control of their disease themselves and a lack of trust of health care professionals in this process; (2) the belief that the National Health Service routine IT systems were unable to support telehealth; and (3) the belief that face-to-face communication was vital in providing them with high-quality care.

Conclusion: Telehealth is considered to be revolutionizing health care and shifting power between patients and health professionals; however, evidence of its effectiveness in delivering improved outcomes for diabetes is limited. The findings presented here suggest that there is a need to understand the context of patients' self-management and their perceptions of their role in telehealth if it is to be successful.

Keywords: patient knowledge, telehealth, self-management, diabetes care, information technology

\section{Introduction}

Diabetes represents one of the biggest public health challenges facing the UK. ${ }^{1}$ It is estimated that 3.8 million people in the UK are living with diabetes and that the figure is expected to increase to 6.25 million by $2035 / 6{ }^{2}$ Diabetes is associated with serious complications including heart disease, stroke, blindness, kidney disease, nerve damage, and amputations, all of which lead to disability and premature mortality. ${ }^{1}$ Diabetes currently costs the National Health Service (NHS) approximately $£ 9.8$ billion for direct patient care (which includes treatment, interventions and management of complications)
Correspondence: Annmarie Ruston Research, Faculty of Health and Social Care, Canterbury Christ Church University, Medway Campus, Cathedral Court, 30 Pembroke Court, Chatham Maritime, Kent ME4 4UF, United Kingdom Tel +440 l 634894473 Fax +44 0I 634894494

Email annmarie.ruston@canterbury.ac.uk 
and a further $£ 13.9$ billion for indirect costs, such as work loss and the need for informal care. ${ }^{2}$

In order to prevent the development of complications and reduce the number of deaths from diabetes, there is a need to increase awareness of the risks, bring about changes in lifestyle and self-management among people with diabetes, and to improve access to integrated diabetes services. ${ }^{1}$ As with many other chronic illnesses, there is a drive to shift some of the burden of routine diabetes management out of the formal health care system by developing patient knowledge and self-awareness through "expert patient" programs. ${ }^{3}$ This has been paralleled with an increase in the implementation of telehealth pilot projects to support patients in the management of their diabetes.

Telehealth has been defined as the use of information, computing, and telecommunications technology to provide health related services, health promotion, and disease management across geographic, time, social, and cultural barriers. ${ }^{4}$ It involves providing health care at a distance using technical artifacts to mobilize representations of and information about patients. ${ }^{5}$

Telehealth interventions for type 1 and type 2 diabetes have incorporated the asynchronous (store and forward) transmission of patient data, mainly blood glucose measurements, and treatment and diet or lifestyle advice by telephone or internet. ${ }^{6}$ Evidence of the effectiveness of telehealth interventions in improving glycemic control or in reducing health care costs, is however, limited. ${ }^{6-9}$ Although systematic reviews have confirmed the feasibility of remote monitoring and home telehealth for a range of disease categories and patient populations, questions remain regarding its efficacy in long-term diabetes control. . $^{8,10}$

Gately et $\mathrm{al}^{11}$ argue that the successful introduction of technology to aid the management of long term conditions is viewed as a technological process, in which the user is assumed to be an active participant in its implementation, but that such assumptions are not necessarily grounded in an understanding about the ways in which patients may engage with, adapt to, and integrate new forms of technology. The way in which telehealth providers respond to the demands and expectations that their patients place on remote care delivery systems, is critical to the future of remotely delivered health care. ${ }^{4}$ Consideration of the patient's view or perceptions in relation to incorporating telehealth into their disease management, is particularly important in the case of people with diabetes as they spend only around $1 \%$ of their time in contact with health professionals, and $99 \%$ of their time self-managing their disease within the constraints of their everyday lives. ${ }^{12}$ Funnell and Anderson ${ }^{13}$ suggest that the serious and chronic nature of diabetes, the complexity of its management, and the multiple daily self-care decisions that people with diabetes must make, means that adherence to predetermined care programs may be difficult. Health care for patients with diabetes needs to be designed to fit patients' priorities, goals, resources, lifestyle, beliefs and knowledge. ${ }^{13}$ These factors also have the potential to affect interaction with, and acceptance of, telehealth.

McLean et $\mathrm{al}^{14}$ argue that although patient's attitudes to telehealth have been extensively studied, with most reporting patients seeing this as a positive development, caution is required when interpreting the findings. In particular, studies are considered to lack depth, and there is an argument for using qualitative approaches, which can generate more rounded, nuanced understandings of patients' experiences and expectations. ${ }^{14}$

Little in-depth, qualitative research has been conducted into the perceptions of diabetes patients about the use of telehealth in the management of their disease, and in their interactions with health professionals. This paper aims to address this gap by examining the perceptions of people with type 1 diabetes about the potential role of telehealth in the management of their disease, and in their interaction with health professionals.

\section{Methods}

The data presented in this paper are drawn from a larger study (Ruston et al, unpublished data, 2011) that aimed to gain an understanding of how diabetes self-management could be supported more effectively using telehealth.

\section{Study design and sample}

The study utilized a national database already housed in our University, of people with type 1 diabetes who use or have used continuous subcutaneous insulin infusion technology (insulin pump). The database was compiled from users of an online support organization, which advocates access to insulin pumps and other diabetes technologies in the UK (Wilson, unpublished data, 2008).

Insulin pumps continually infuse insulin into the subcutaneous tissue at a rate that is preset according to the type 1 diabetic patient's needs, with patient activated boosts when food is eaten. The diabetic patient sets the insulin dose according to his or her diet, exercise, and blood glucose 
levels, and it is recommended that blood glucose is checked four times a day to obtain the information needed to set the appropriate insulin dose. Insulin pump technology has the functionality to electronically record, and share data with a health care professional. Recruitment continued until data saturation was reached.

A total of 32 diabetics were interviewed, including 20 females and 12 males. Of these, 23 were currently using insulin pump therapy, and nine were using multiple daily injections having used an insulin pump in the past.

\section{Data collection}

Respondents were approached by telephone and their treatment mode ascertained, the study was explained to them, and a suitable time agreed for interview. Telephone interviews were conducted due to the geographical spread of the sample. The interviews were semistructured and covered participants' perceptions about the potential role of telehealth in the management of their disease, communication with health professionals using telehealth, who they considered to be responsible for the management of the disease, the barriers they encountered in self-management, factors that facilitated good management, and what could be done to support them.

The study gained University ethics approval for access to patients from the database. Verbal consent was obtained from respondents at the time of telephone interview.

\section{Data analysis}

The interviews, lasting between 30 and 40 minutes, were tape recorded and transcribed. Preliminary analysis was undertaken concurrently with data collection to identify emerging themes and ensure that sufficient respondents were recruited to achieve data saturation on all elements of the overall study. Initial analysis was conducted using a constant comparative approach. ${ }^{15}$ Each transcript was separately read by two members of the research team to identify emerging categories of data or themes. The transcripts were reread, and categories compared with one another to identify similarities and differences. The categories were then refined to ensure that the concepts, relations between variables, and differences between the themes could be confirmed or modified as necessary.

\section{Results}

The age, sex, mode of treatment, length of time since diagnosis, and occurrence of complications and hypoglycemic events of individual respondents are shown in Table 1.
All respondents reported that they used IT as part of their everyday lives, and described using technology as part of their self-management of their diabetes. The majority (25) also reported downloading results to their computer to help them monitor or fine tune their diabetes management:

I use a pump combined with a Life Scan blood glucose meter and also software that comes with the Life Scan meter, which I then download into my computer, which gives me a good reference as to how I'm doing. ... It is useful it enables me to fine tune the basal rates [levels of insulin delivery] on the pump to give me the best control. [Interview 3]

My blood machine does actually upload onto a computer. I don't like the software it came with and my husband has devised a system where we upload the information and then drag the blood sugars out of it and into a chart that makes more sense. [Interview 14]

Of the seven respondents that did not download data from their insulin pumps or blood glucose meters, three said they did not know how to use the technology to download results, and four said they did not have the motivation to do this.

When asked if they had heard of telehealth, most respondents said they had not heard of the term but were able to describe activities which constituted telehealth. Three respondents described situations where they had engaged in telehealth as part of their health care. However, when asked about the value of using telehealth as part of their diabetes management, they considered it to have a number of limitations.

Three themes emerged from their discourses about telehealth, and the management of their diabetes: (1) a need to be in control of their disease themselves and a lack of trust of others in this process; (2) the belief that the NHS routine IT systems were unable to support telehealth; and (3) the belief that face-to-face communication was vital in providing them with high quality care.

\section{Self in control and lack of trust in others in this process}

The average number of years that respondents had been living with diabetes was 29 and, as a consequence, they considered that they possessed their own, unique understanding of their diabetes. They considered themselves to be experts in the management of their own disease:

When I was a kid my diabetes ran like the book says, straightforward, but now all my levels start doing really 
Table I Sample characteristics

\begin{tabular}{|c|c|c|c|c|c|c|}
\hline $\begin{array}{l}\text { Respondent } \\
\text { number }\end{array}$ & Sex & $\begin{array}{l}\text { Age } \\
\text { (years) }\end{array}$ & $\begin{array}{l}\text { Treatment } \\
\text { and type }\end{array}$ & $\begin{array}{l}\text { Length of time since } \\
\text { diagnosis (years) }\end{array}$ & $\begin{array}{l}\text { Reported at least one complication } \\
\text { arising from diabetes? }\end{array}$ & $\begin{array}{l}\text { Has hypoglycemic } \\
\text { events? }\end{array}$ \\
\hline 1 & $\mathrm{~F}$ & 45 & Injections type I & 17 & No & Yes \\
\hline 2 & $\mathrm{~F}$ & 49 & Pump type I & 38 & No & Yes \\
\hline 3 & $M$ & 65 & Pump type I & 21 & Yes & Yes \\
\hline 4 & $\mathrm{~F}$ & 41 & Pump type I & 31 & Yes & Yes \\
\hline 5 & $M$ & 44 & Injections type I & 40 & Yes & Yes \\
\hline 6 & $M$ & 59 & Injections type I & 36 & No & No \\
\hline 7 & $\mathrm{~F}$ & 58 & Pump type I & 26 & No & No \\
\hline 8 & $\mathrm{~F}$ & 33 & Pump type I & 21 & No & No \\
\hline 9 & $M$ & 62 & Pump type I & 16 & Yes & Yes \\
\hline 10 & $M$ & 33 & Injections type I & 21 & No & Yes \\
\hline II & $M$ & 53 & Pump type I & 26 & Yes & Yes \\
\hline 12 & $\mathrm{~F}$ & 48 & Pump type I & 37 & No & Yes \\
\hline 13 & $\mathrm{~F}$ & 39 & Pump type I & 31 & Yes & Yes \\
\hline 14 & $\mathrm{~F}$ & 30 & Pump type I & 29 & Yes & Yes \\
\hline 15 & $\mathrm{~F}$ & 64 & Pump type I & 42 & Yes & Yes \\
\hline 16 & M & 60 & Injections type I & 30 & No & No \\
\hline 17 & $M$ & 45 & Pump type I & 21 & Yes & No \\
\hline 18 & $\mathrm{~F}$ & 62 & Injections type I & 15 & No & Yes \\
\hline 19 & $\mathrm{~F}$ & 54 & Injections type I & 22 & Yes & Yes \\
\hline 20 & $\mathrm{~F}$ & 50 & Pump type I & 26 & No & No \\
\hline 21 & $\mathrm{~F}$ & 55 & Pump type I & 20 & No & Yes \\
\hline 22 & $M$ & 65 & Pump type I & 64 & Yes & Yes \\
\hline 23 & $\mathrm{~F}$ & 65 & Pump type I & 40 & No & No \\
\hline 24 & $M$ & 46 & Pump type I & 43 & Yes & Yes \\
\hline 25 & $\mathrm{~F}$ & 53 & Pump type I & 50 & Yes & Yes \\
\hline 26 & $\mathrm{~F}$ & 64 & Pump type I & 13 & No & Yes \\
\hline 27 & $\mathrm{~F}$ & 40 & Pump type I & 26 & No & Yes \\
\hline 28 & $\mathrm{~F}$ & 50 & Pump type I & 20 & No & Yes \\
\hline 29 & $\mathrm{~F}$ & 44 & Pump type I & 31 & Yes & No \\
\hline 30 & $\mathrm{~F}$ & 53 & Pump type I & 22 & Yes & No \\
\hline 31 & $M$ & 54 & Injection type I & 40 & Yes & Yes \\
\hline 32 & $M$ & 45 & Injection type I & 30 & No & Yes \\
\hline
\end{tabular}

kooky things, and because of that I've sort of invented my own ways of dealing with it. [Interview 14]

I rely on "feelings" to manage my diabetes, and to decide whether to check my blood sugar. [Interview 32]

Rather than rely on my pump, I alter the insulin dose myself. I would rather alter it myself and I keep testing my blood - well I don't think we are all the same. I don't think our bodies use the insulin and the sugar at the same pace. [Interview 20]

This belief that they possessed a unique intelligence about their own disease was coupled with a lack of trust in the knowledge base of the health professionals who were there to support them:

My body acts differently to others'. Personally, I find that I'm the best person who knows what to do and there are only a few people I trust to help me manage and control my diabetes. [Interview 2]
I've been a diabetic for so long I know more about my diabetes than they [health professionals] will ever know. [Interview 5]

I feel that I manage my diabetes myself. ... I don't have a lot of trust in other people I prefer to control it myself. [Interview 1]

Respondents' discourses revealed a general concern about whether certain health professionals, particularly those from primary care, had sufficient knowledge or expertise to deliver good quality diabetic care to patients with type 1 diabetes:

I've had appointments with GPs and they've never even seen an insulin pump let alone, you know, heard about it. Any they'll say to me, "Well, I'm sorry. I really don't know." And with the condition of neuropathy [nerve damage caused by diabetes] that I have, if I then have to increase my pain relief, nobody understands the management of it. So I really try to make sure I have back up from my diabetes centre. [Interview 30] 
I wouldn't ring the GP, I seem to know more about it than they do. I would always go to my diabetic consultant, or my diabetic pump team at the hospital. [Interview 22]

I certainly wouldn't consider giving them [blood glucose results] to my GP as I don't think he would understand them, but I might to my diabetes practice nurse. [Interview 2]

The nurse tends to ask the questions and I tend to advise her! [Interview 3]

Those respondents who were unable to gain support from their local NHS for their insulin pump reported having to rely on their own skills and having to obtain information from the pump manufacturers, rather than their health professionals.

\section{Routine NHS IT systems not compatible with their technology}

Respondents reported that, although the technology they used to manage their diabetes had the potential to provide important information that could be used by health professionals, they were unable to utilize it due to system incompatibility:

Well certainly, when I was trialing the continual blood glucose monitor sensors, I was given a package so that we could download the information but the hospital network couldn't cope with the system, so I ended up having to download it onto my own laptop, and physically taking it to the hospital so they could look at it ... You would think that the fact that the hospital are purchasing these Medtronic and Dissertronic pumps, that they should be able to cope with the IT set up. But they can't. [Interview 30]

My insulin pump does keep a record of my sugar levels and if the hospital clinic had the software I could download them but they don't have the software for my pump. [Interview 2]

The practice does not take email attachments so cannot send my results through, and my pump software is not compatible with their computer system. [Interview 5]

In addition to problems with compatibility, some respondents also reported that where they had transformed their data to a format that was accessible, such as on a data stick or in hard copy format, there was no guarantee that it would be utilized. For example, the following respondent downloaded his results onto a data stick but it was not used because of the hospital policy around data security:
Well last time I went [to the clinic], I was very annoyed because this pump comes with the software to put your results on a memory stick and I had all this. I took it along to the consultation. "Oh no, we can't look at that! We're not allowed to put anything like that on our computer" [they told me]. So I had to rely on what my own analysis of it was, rather than them looking at the actual figures. [Interview 24]

Another took their results in hard copy but found that it was still not looked at:

I download information from my meter to my PC and then print it out and take it to my 6 monthly review because they don't have the software, but they don't actually look at it. [Interview 6]

When discussing the use of telehealth to ask their health care team for support or information, respondents felt that a shortage of staff time would preclude any meaningful feedback, if indeed they were to get any feedback:

I don't see a problem with doing it [telehealth] but I'd like to know where they [NHS staff] are going to get the time to sit in front of a computer and read your results, and give you feedback. [Interview23]

I don't think it would work [telehealth] because the kind of doctors and GPs and consultants I know, they're not going to be ringing you back. They might have a thousand patients on their books. They can't all be on the phone. [Interview 9]

When I first got my pump the nurse said, "I've got this man who continually sends me all his test results and it drives me mad!” And I thought if everybody was continually sending their results they'd never get anything done. [Interview 26]

Where respondents reported having access to support via the telephone or email, they felt it was of limited value because it was provided asynchronously rather than in real time:

I do have a telephone service for problems but it is not an instantaneous service. You have to leave a message and it could be two days before they get back to you. [Interview 14]

If I have a problem with my diabetes I would prefer to speak to someone direct and I'm not sure that by downloading or passing emails or sharing my information by computer to another health department, I don't think, in my opinion, that it would be of any benefit to me. I want to be able to pick 
up the phone and say "I've got real problems with my sugar levels and I've tried everything - what can you do to help." I want to be able to discuss it immediately. [Interview 1]

\section{Need for face-to-face consultations}

Linked to the wish for "real time" information, respondents talked about the need for face-to-face interaction between themselves and their health professionals, in order to solve problems, and check out and explain advice. The majority of respondents considered that the management of their diabetes would be best served by face-to-face consultations rather than via telehealth:

I do think that you need certain contact [with health professionals] because certainly, thinking about situations I've been in, when people have seen me, they've understood exactly how bad things are. But if you are discussing results all the time over the Internet or by telephone, you know, people don't necessarily understand what you are physically going through. I do understand from information I've read and stuff, that sometimes people say that they are managing their diabetes when in fact they are not. And, you know, if you are just passing information via the Internet like that, nobody's really got a handle on what's going on. But when you physically see people and talk to them, you know when they understand things and when they don't. I still think it's very important. [Interview 30]

I think face-to-face communication is really important. If you are just dealing with information you could send it in the post. You need to receive some interaction and for him to say to you, "Have you tried this?" And you say, "I have, but I have had a problem." And then he says, "Ah, well we can get around that by doing this." To me, I would imagine that any problem you had would take a lot longer to resolve [with telehealth] because you would be battling requests regularly through the technology, rather than something that could be resolved in about five minutes face-to-face. [Interview 2]

It [telehealth] would be useful but I could see problems with it. If it was going to be, you know, like on the basis of just sending blood sugar results. There are lots of other things that come into diabetes care that if you are talking to the specialist nurse, and something would come up and you'd say, "Is that why that happened?", or "Should I have done this?" I think you are better facing someone to discuss these things. [Interview 23]

Respondents in this study demonstrated a need to remain in control of the management of their diabetes as well as the belief they had a unique understanding of their own disease, and indicated that whilst the use of technology held some utility, it would need to be used in a way that would provide effective support. They suggested that there were a number of potential limitations to the implementation of telehealth in relation to the management of their disease including, IT incompatibility, a lack of knowledge amongst health professionals, and a need to have face-to-face consultations.

\section{Discussion}

Farmer et $\mathrm{al}^{7}$ suggest that care of patients with diabetes provides an exemplar for the management of people with chronic disease. Current clinical pathways for supporting patients with diabetes involve either frequent visits to clinics; or routine visits supplemented by telephone support, to exchange information about blood glucose results, and to provide advice on adjusting treatment. ${ }^{16}$ These are time consuming, and the integration of primary and secondary care management, the encouragement of self-management, and the systematic monitoring of measures of disease progression and control, are complex issues that may lead to problems that are difficult to resolve. ${ }^{7}$ There is the potential for telehealth to solve such problems and, indeed, use of telehealth is considered to have the potential to revolutionize health care provision. ${ }^{17}$ This is premised on the idea that teleheath will improve the efficiency of services, by enabling faster access to community health professionals and support for chronic disease management.

However, although there have been many trials of telehealth in the UK, such services typically fail to become part of routine health care delivery, ${ }^{18}$ particularly for long term diabetes control. ${ }^{8,10}$

Mort et $\mathrm{al}^{19}$ argue that although patients have been characterized in policy documents as being informed, responsible, and capable of being wirelessly linked to services, they have been silent in the design and development of telehealth systems. They suggest that the absence of the patient from the process of producing knowledge about the patient who receives telehealth, restricts the possibility of achieving workability in practice. ${ }^{19}$

The findings of this study provide valuable insights into perceptions of patients with type 1 diabetics about the potential value and problems associated with the use of telehealth to support the management of their disease. Although respondents appeared to meet the requirements of chronic disease patients (characterized in policy documents) as suitable for telehealth services, ie, experts in the management of their disease, employing self-care, and technologically connected, ${ }^{3}$ they identified a range of problems 
they perceived as a barrier to their use of telehealth. Three main issues emerged:

Firstly, they expressed a need to remain in control of their disease management and considered that telehealth could alter the power relations/balance between themselves and their health professionals. This in turn, they felt, had the potential to undermine the management of their disease, because they considered some health professionals to be less knowledgeable than they were about the disease.

Secondly, even though the majority of respondents were able to use technology to facilitate the management of their disease, they identified a number of factors that acted as barriers including, the lack of compatibility of IT systems, lack of NHS staff time, and an inability of the NHS to deliver real time support. Given the customized nature of the insulin pumps and blood glucose meters used by diabetics, connectivity presents a challenge for the NHS.

Thirdly, they considered that face-to-face consultation was of key importance in supporting them to manage their disease appropriately and that only within this context, could they receive quality care.

The engagement of patients in the coproduction of knowledge about the design and implementation of telehealth has been absent, having been, according to Mort et al, ${ }^{19}$ ghettoized within the legitimizing device of the patient satisfaction survey. Thus although patients may be supportive of telehealth, this is not the same as having views about how it may be effectively implemented in relation to their own chronic disease, and such views would need to be taken into consideration to achieve successful implementation.

Respondents in this study had been self-managing their complex disease for many years and most received care from a diabetes specialist, and as such, they provide an ideal group to explore issues around the implementation of telehealth. However, the findings may not be as relevant for people with type 2 diabetes as this does not necessarily require the same degree of self-management as type 1 diabetes.

\section{Conclusion}

Although telehealth is considered to be revolutionizing health care delivery and shifting power relationships between patients and health professionals, evidence of its effectiveness in delivering improved outcomes for the provision of diabetes services is limited. The findings of the study reported in this paper suggest that if teleheath is to be successfully implemented, better understanding of the context of diabetes self-management, and of patients' perceptions of the role they would play in services delivered using telehealth, is needed. The interesting and important findings of this study are firstly, that respondents reported an inability to share their patient generated electronic data with NHS systems; secondly, that NHS health care professionals were not generally interested in such data, did not know how to use it, did not have the time to use it, and did not trust it; and thirdly, that respondents believed face-to-face consultations were necessary for the care of type 1 diabetes. All three barriers could form barriers to telehealth in the management of type 1 diabetes, especially in the context of newly introduced technology such as continuous subcutaneous insulin infusion or insulin pumps.

\section{Disclosure}

The authors report no conflicts of interest in this work.

\section{References}

1. Diabetes UK. Diabetes in the UK 2010: Key Statistics on Diabetes. Diabetes UK; 2010. Available from: http://www.diabetes.org.uk/Documents/ Reports/Diabetes_in_the_UK_2010.pdf. Accessed August 1, 2012.

2. Hex N, Bartlett C, Wright D, Taylor M, Varley D. Estimating the current and future costs of Type 1 and Type 2 diabetes in the UK, including direct health costs and indirect societal and productivity costs. Diabetic Med. 2012;29(7):855-862.

3. May C, Finch T, Mair F, Mort M. Towards a wireless patient: chronic illness, scarce care and technological innovation in the United Kingdom. Soc Sci Med. 2005;61:1485-1494.

4. Darkins A, Cary M. Telemedicine and telehealth. Principles, Policies, Performance and Pitfalls. London: Free Association Books; 2000.

5. Finch TL, Mort M, Mair FS, May CR. Future Patients? Telehealthcare, roles and responsibilities. Health Soc Care Community. 2008;16(1): 86-95.

6. Charpentier G, Benhamou PY, Dardari D, et al; TeleDiab Study Group. The Diabeo software enabling individualized insulin dose adjustments combined with telemedicine support improves HbA1c in poorly controlled type 1 diabetic patients: a 6-month, randomized, open-label, parallel-group, multicenter trial (TeleDiab 1 Study). Diabetes Care. 2011;34(3):533-539.

7. Farmer A, Gibson O, Hayton P, et al. A real-time, mobile phone-based telemedicine system to support young adults with type 1 diabetes. Inform Prim Care. 2005;13(3):171-177.

8. Dellifraine JL, Dansky KH. Home-based telehealth: a review and meta-analysis. J Telemed Telecare. 2008;14(2):62-66.

9. Montori V, Helgemoe PK, Guyatt GH, et al. Telecare for patients with type 1 diabetes and inadequate glycemic control: a randomized controlled trial and meta-analysis. Diabetes Care. 2004;27(5):1088-1094.

10. Istepanian RS, Zitouni K, Harry D, et al. Evaluation of a mobile phone telemonitoring system for glycaemic control in patients with diabetes. J Telemed Telecare. 2009;15(3):125-128.

11. Gately C, Rogers A, Kirk S, McNally R. Integration of devices into long-term condition management: a synthesis of qualitative studies. Chronic Illn. 2008;4(2):135-148.

12. Hinder S, Greenhalgh T. "This does my head in”. Ethnographic study of self-management by people with diabetes. BMC Health Serv Res. 2012;12:83.

13. Funnell MM, Anderson RM. Empowerment and self-management of diabetes. Clinical Diabetes. 2004;22(3):123-127

14. McLean S, Protti D, Sheikh A. Telehealthcare for long term conditions $B M J$ [serial on the internet]. February 3, 2011. doi:10.1136/bmj.d120 http://www.bmj.com/content/342/bmj.d120.full. Accessed July 31, 2012. 
15. Maycut P, Morehouse R. Beginning Qualitative Research: A Philosophic and Practical Guide. London: The Falmer Press; 1994.

16. Turner J, Larsen M, Tarassenko L, Neil A, Farmer A. Implementation of telehealth support for patients with type 2 diabetes using insulin treatment: an exploratory study. Inform Prim Care. 2009;17(1):47-53.

17. Finch $T$. Teledermatology for chronic disease management: coherence and normalization. Chronic Illn. 2008;4(2):127-134.
18. Finch T, May C, Mair F, Mort M, Gask L. Integrating service development with evaluation in telehealthcare: an ethnographic study. BMJ. 2003;327(7425):1205-1209.

19. Mort M, Finch T, May C, Mair F, Mort M, Gask L. Making and unmaking telepatients: identity and governance in new health technologies. Sci Technol Human Values. 2009;34(1):9-33.

\section{Publish your work in this journal}

Patient Intelligence is an international, peer-reviewed, open access journal that characterizes and measures the central role of patient behavior and intention in optimizing healthcare management in all areas of disease and complaint types. An improved understanding of patient intelligence coupled with predictive analysis helps an organization contribute more effectively to achieving better outcomes.

Submit your manuscript here: http://www.dovepress.com/patient-intelligence-journal
Dovepress

The journal is characterized by the rapid reporting of reviews, original research, methodologies, analytics, modeling, clinical studies and patient surveys across all disease areas. The manuscript management system is completely online and includes a very quick and fair peer-review system. Visit http://www.dovepress.com/ testimonials.php to read real quotes from published authors. 